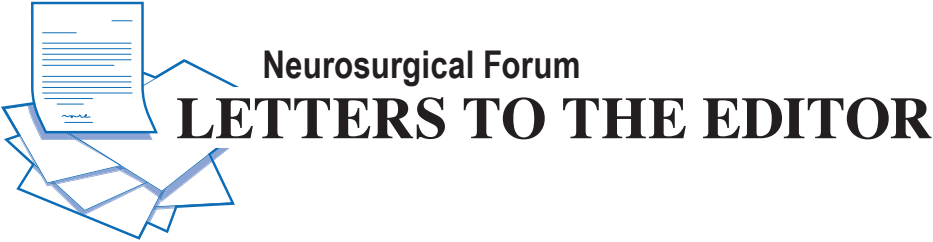

\section{Should we really avoid the supine position in patients with spinal cord injury who undergo laminectomy?}

TO THE EDITOR: We have read with great interest the paper by Phang et al. ${ }^{2}$ (Phang I, Zoumprouli A, Saadoun S, et al: Safety profile and probe placement accuracy of intraspinal pressure monitoring for traumatic spinal cord injury: Injured Spinal Cord Pressure Evaluation study. J Neurosurg Spine 25:398-405, September 2016). The article is well written, and the authors have demonstrated the accuracy and safety of intradural pressure monitoring. However, they also postulated that the supine position should be avoided in patients with spinal cord injury (SCI) who undergo laminectomy, which seems to be inconsistent with the clinical practice. In our clinical practice, patient positioning postlaminectomy should be changed every 2 to 3 hours, often from supine to lateral and vice versa, to prevent the development of pressure ulcers. The authors did not investigate the relationships between patient positioning and neurological outcome in this paper. Still, there is no evidence to date that the patients in the supine position postlaminectomy would experience worse functional recovery than in the lateral position.

Actually, although the difference of intraspinal pressure ( $\triangle \mathrm{ISP}$ ) was up to $18 \mathrm{~mm} \mathrm{Hg}$ after thoracic laminectomies, and up to $8 \mathrm{~mm} \mathrm{Hg}$ after cervical laminectomies, the average difference was approximately $2 \mathrm{~mm} \mathrm{Hg}$ and 1 $\mathrm{mm} \mathrm{Hg}$, respectively. It seems that the authors were exaggerating the difference of ISP in the supine versus lateral position. In another retrospective study of traumatic brain injury, Aries et al. ${ }^{1}$ found that patients with a median cerebral perfusion pressure (CPP) close to the optimum CPP (CPPopt) were more likely to have a favorable outcome than those in whom the median CPP was widely different from CPPopt. Similarly, in traumatic SCI, either too high or too low spinal cord perfusion pressure (SCPP) is detrimental to the neurological recovery. Because the SCPP is computed as the mean arterial pressure minus ISP, the increase of ISP with subsequent decrease of SCPP to some extent in the supine position would not necessarily result in worse functional outcome.

Although this article is retrospective and the number of patients is limited, it opened a new window for us to look into the ISP in relation to different patient positioning.
Future studies are needed to further explore the relationships between patient positioning, ISP, and neurological outcome.

Fubing Liu, MD
Bing Wang, MD, PhD
Yunchao Li, MD
Guohua Lv, MD
The 2nd Xiangya Hospital of Central South University,
Changsha, Hunan, China
Xiaoxing Jiang, MD
Zhongshan Hospital of Fudan University, Shanghai, China

\section{References}

1. Aries MJ, Czosnyka M, Budohoski KP, Steiner LA, Lavinio A, Kolias AG, et al: Continuous determination of optimal cerebral perfusion pressure in traumatic brain injury. Crit Care Med 40:2456-2463, 2012

2. Phang I, Zoumprouli A, Saadoun S, Papadopoulos MC: Safety profile and probe placement accuracy of intraspinal pressure monitoring for traumatic spinal cord injury: Injured Spinal Cord Pressure Evaluation study. J Neurosurg Spine 25:398-405, 2016

\section{Disclosures}

The authors report no conflict of interest.

\section{Response}

We agree with Liu et al. that patients with SCIs should be turned in bed to prevent the development of pressure sores. The point we tried to make is that, when patients with SCIs who had laminectomy are being turned, one should avoid compressing the wound. This usually occurs when patients with thoracic SCIs who have undergone laminectomy lie supine, especially if a pillow is placed under the wound. The supine position is acceptable, but pillows or folded towels should then be used to take the pressure off the wound. In a patient with SCI who had undergone a laminectomy, compression of the wound is transmitted to the injured spinal cord, causing a rise in ISP and a drop in SCPP, with potentially catastrophic consequences. Because ISP monitoring is a new technique, we have not yet investigated whether patient position in bed has an impact on neurological outcome.

Liu et al. also refer to the interesting concept of continuous CPPopt, which has been proposed to aid the management of patients with brain injuries in the neurointen- 
sive care unit. We are currently investigating relationships between ISP and SCPP versus neurological outcome. We are also investigating whether the concept of a continuous CPPopt, which can be displayed in real time on a monitor to guide patient management in the neurointensive care unit, also applies to SCI.

We find all of the points raised by Liu et al. fascinating. These and other points are discussed in detail in our forthcoming review. ${ }^{1}$ We would encourage Liu et al., as well as others who treat patients with acute SCIs, to try monitoring ISP in their centers. They will then be able to judge for themselves whether such monitoring is clinically useful. They will also be able to investigate independently the various points raised here; e.g., the relationship between patient position, injury site perfusion, and outcome. We would like to see ISP monitoring introduced in centers outside our own. Only then will it become possible to perform a randomized, controlled, multicenter trial to definitively establish whether ISP monitoring and optimization improve outcome.

\section{Isaac Phang, MRCS Argyro Zoumprouli, MD Samira Saadoun, PhD Marios C. Papadopoulos, MD, FRCS(SN) St. George's Hospital, London, United Kingdom}

\section{References}

1. Saadoun S, Papadopoulos MC: Spinal cord injury: is monitoring from the injury site the future? Crit Care 20:308, 2016

INCLUDE WHEN CITING

Published online January 6, 2017; DOI: 10.3171/2016.10.SPINE161149.

(cAANS, 2017

\section{Strategic use of cone-beam CT in modern spine surgery}

TO THE EDITOR: We read with great interest the article by Dr. Costa and colleagues ${ }^{1}$ (Costa F, Tosi G, Attuati L, et al: Radiation exposure in spine surgery using an image-guided system based on intraoperative cone-beam computed tomography: analysis of 107 consecutive cases. J Neurosurg Spine 25:654-659, November 2016). The authors concluded that the $\mathrm{O}$-arm system (Medtronic, Inc.) exposes patients to a higher radiation dose than does standard fluoroscopy. However, we respectfully would like to offer a different opinion regarding the issue of radiation safety in using the $\mathrm{O}$-arm system.

First, there was a mismatch between the number of patients described in the abstract $(\mathrm{n}=107)$ and in the Results ( $\mathrm{n}=108 ; 2$ cases had 1 scan, 99 cases had 2, and 7 cases had 3 scans). In other words, $91.6 \%(99 / 108)$ of the patients were scanned twice, and 6.5\% (7/108) were scanned 3 times with the $\mathrm{O}$-arm. These multiple $\mathrm{O}$-arm scans, which were conducted in more than $98 \%$ of the patients in the current series, inevitably increased the dose of radiation exposure and might be avoided. For instance, the final-check scan (i.e., prior to the patient leaving the operating room) is usually used only for confirmation and often can be omitted.

Using $\mathrm{O}$-arm scans and navigation for screw placement has the most merit in spine surgery involving multiple segments, such as deformity and minimally invasive spine surgery, because it requires only $1 \mathrm{O}$-arm scan to register the navigation for all screws. The current study calculated that a single O-arm scan exposed the patient to $2.52 \mathrm{mSv}$. In conventional fluoroscopy-guided percutaneous screw placement, the radiation dose to the patient greatly depends on the number of fluoroscopies taken and thus is subject to the individual operator's technique. The more segments of fluoroscopic guidance used in spine surgery, the higher the radiation exposure in the patient.

A meta-analysis estimated that the average dose of fluoroscopic radiation exposure in a patient who had a 1-level (i.e., 4 screws) minimally invasive transforaminal lumbar interbody fusion (TLIF) procedure would be 1.58 $\mathrm{mSv} .^{2-7}$ There were few data in the literature on the exposure in patients in whom 2-level minimally invasive TLIF (i.e., 6 screws) was performed using fluoroscopy, which is also commonly encountered in spine practice. However, it can be deduced from the above to be $2.37 \mathrm{mSv}(1.58 / 4 * 6)$. Thus, there is actually little difference in exposure to radiation in the patient between using the $\mathrm{O}$-arm and fluoroscopy when placing 6 percutaneous screws. One O-arm scan is usually adequate to navigate screw insertion in up to 5 or 6 vertebral segments of the thoracolumbar spine. Therefore, fluoroscopy is likely to involve more radiation exposure in the patient than the O-arm when 4 or more vertebral segments are targeted.

There have been no guidelines regarding radiation safety for patients who undergo spine surgery. The issue of radiation has drawn increasing attention as minimally invasive spine surgery has become prevalent, because image guidance is particularly useful for percutaneous screw insertion. We commend the authors for addressing the patients' dosage of radiation exposure per O-arm scan in the thoracolumbar spine. Moreover, when using the O-arm with navigation, the radiation exposure of surgeons, anesthesiologists, and nurses is essentially zero, compared to that during fluoroscopic guidance. This advantage should be highlighted and is especially critical for staff working in high-volume spine centers. Because the patients' risk of radiation exposure remains unknown, and the effective dose of fluoroscopic guidance is seldom reported, further investigations are needed to ascertain a balance between fluoroscopy and $\mathrm{O}$-arm in these spine surgeries.

Chih-Chang Chang, MD',2
Li-Yu Fay, MD',2
Jau-Ching Wu, MD, PhD',2
Peng-Yuan Chang, MD',4
Tsung-Hsi Tu, MD ${ }^{1-3}$
Henrich Cheng, MD, PhD
Wen-Cheng Huang, MD, PhD
W,2
${ }^{1}$ Neurological Institute, Taipei Veterans General Hospital, Taipei, Taiwan
${ }^{2}$ School of Medicine, National Yang-Ming University, Taipei, Taiwan
${ }^{3}$ Taiwan International Graduate Program in Molecular Medicine,
National Yang-Ming University and Academia Sinica, Taipei, Taiwan


${ }^{4}$ Taoyuan General Hospital, Ministry of Health and Welfare, Taoyuan, Taiwan

\section{References}

1. Costa F, Tosi G, Attuati L, Cardia A, Ortolina A, Grimaldi $M$, et al: Radiation exposure in spine surgery using an imageguided system based on intraoperative cone-beam computed tomography: analysis of 107 consecutive cases. J Neurosurg Spine 25:654-659, 2016

2. Kim $\mathrm{CH}$, Lee $\mathrm{CH}$, Kim KP: How high are radiation-related risks in minimally invasive transforaminal lumbar interbody fusion compared with traditional open surgery?: A metaanalysis and dose estimates of ionizing radiation. Clin Spine Surg 29:52-59, 2016

3. Lee KH, Yue WM, Yeo W, Soeharno H, Tan SB: Clinical and radiological outcomes of open versus minimally invasive transforaminal lumbar interbody fusion. Eur Spine J 21:2265-2270, 2012

4. Ntoukas V, Müller A: Minimally invasive approach versus traditional open approach for one level posterior lumbar interbody fusion. Minim Invasive Neurosurg 53:21-24, 2010

5. Peng CW, Yue WM, Poh SY, Yeo W, Tan SB: Clinical and radiological outcomes of minimally invasive versus open transforaminal lumbar interbody fusion. Spine (Phila Pa 1976) 34:1385-1389, 2009

6. Seng C, Siddiqui MA, Wong KP, Zhang K, Yeo W, Tan SB, et al: Five-year outcomes of minimally invasive versus open transforaminal lumbar interbody fusion: a matched-pair comparison study. Spine (Phila Pa 1976) 38:2049-2055, 2013

7. Wang J, Zhou Y, Zhang ZF, Li CQ, Zheng WJ, Liu J: Comparison of one-level minimally invasive and open transforaminal lumbar interbody fusion in degenerative and isthmic spondylolisthesis grades 1 and 2. Eur Spine J 19:1780-1784, 2010

\section{Disclosures}

The authors report no conflict of interest.

\section{Response}

We kindly thank Chang et al. for their considerations regarding our paper. In particular, I appreciate the different opinions and topics analyzed that are a source of discussion.

Regarding the mismatch of the number of patients described in the text, I have double-checked the series presented in the paper. I apologize for this error: in fact, the series consisted of 107 cases, and in the Results section there was an error in the number of cases in which 2 scans were obtained. The correct number is 98 , and not 99 as previously written.

As a matter of fact, radiation safety is a crucial matter in spine surgery, and there can be differences in analyzing evaluations. On one hand, we have the patient's perspective, whereas on the other hand we have the surgical staff's perspective.

For patients, it is essential to obtain an acceptable balance between the safety of screw placement and radiation exposure. Image-guided systems (IGSs) based on intraoperative imaging (such as the O-arm system) provide excellent results regarding accuracy, achieving up to $99.2 \%,{ }^{1}$ which is significantly higher than the accuracy of a standard fluoroscopic technique, referenced as $90.3 \%{ }^{3}$ Analyzing the results regarding radiation exposure in this study or in similar papers ${ }^{4}$ shows that the main doses for patients, using an IGS that is based on intraoperative CT scans, may vary from $5.15 \mathrm{mSv}$ to $5.69 \mathrm{mSv}$, which is higher than in other fluoroscopic techniques. However, as stated by Chang et al., the doses reached in the conventional fluoroscopic technique depend on various factors, such as the number of levels and the experience of the surgeon.

In fact, as underlined in the Discussion, and as suggested by Chang et al., doses with the $\mathrm{O}$-arm system may be optimized, with a significant reduction in the final dose. In particular, considering that the accuracy of screw placement reaches more than $99 \%$, a control scan can usually be avoided and considered only when faced with cases in which there is doubt. Moreover, by using collimation or minimizing the parameters of the device, as demonstrated by $\mathrm{Su}$ et al., ${ }^{5}$ it is possible to reduce the doses further, thus obtaining a radiation exposure that is acceptable and comparable to standard fluoroscopy.

Analyzing the impact of radiation exposure with regard to the surgical staff, our study showed that the final dose is negligible, as with an IGS. Obviously this is a crucial point, especially for staff working in high-volume spine centers. In fact, with this system the radiation dose remains below the recommendations of the International Commission on Radiological Protection. ${ }^{2}$

In conclusion, in our experience the $\mathrm{O}$-arm system represents a valuable tool for modern spine surgery, granting an acceptable balance between effectiveness of procedure and radiation safety, for both the patients and the surgical teams. Considering that it is widespread over the world (more than 1000 devices), I think that its use should be optimized and regulated, especially with regard to the use of a control scan and better dose collimation. Further studies may suggest a greater indication and role for the use of these devices in spine surgery.

\section{Francesco Costa, MD \\ Humanitas Clinical and Research Center, Rozzano, Milan, Italy}

\section{References}

1. Costa F, Dorelli G, Ortolina A, Cardia A, Attuati L, Tomei $\mathrm{M}$, et al: Computed tomography-based image-guided system in spinal surgery: state of the art through 10 years of experience. Neurosurgery 11 (Suppl 2):59-68, 2015

2. International Commission on Radiological Protection: The 2007 Recommendations of the International Commission on Radiological Protection. ICRP Publication 103. Ottawa: ICRP, 2007

3. Kosmopoulos V, Schizas C: Pedicle screw placement accuracy: a meta-analysis. Spine (Phila Pa 1976) 32:E111-E120, 2007

4. Mendelsohn D, Strelzow J, Dea N, Ford NL, Batke J, Pennington A, et al: Patient and surgeon radiation exposure during spinal instrumentation using intraoperative computed tomography-based navigation. Spine J 16:343-354, 2016

5. Su AW, Luo TD, McIntosh AL, Schueler BA, Winkler JA, Stans AA, et al: Switching to a pediatric dose O-arm proto$\mathrm{col}$ in spine surgery significantly reduced patient radiation exposure. J Pediatr Orthop 36:621-626, 2016

INCLUDE WHEN CITING

Published online January 13, 2017; DOI: 10.3171/2016.9.SPINE161054.

(c)ANS, 2017 